\title{
MARTIN BRAUNWIESER NA VIAGEM DA MISSÃO DE PESQUISAS FOLCLÓRICAS (1938): DIÁRIO E CARTAS*
}

\author{
Álvaro L. R. S. Carlini \\ Doutorando no Depto. de História-FFLCH/USP
}

RESUMO: O artigo relata, através de excertos inéditos do diário e de correspondências, a participação do maestro austríaco Martin Braunwieser (1901-1991) na viagem da Missão de Pesquisas Folclóricas de 1938. Esta expedição etnográfica foi o último projeto idealizado por Mário de Andrade à frente do Departamento de Cultura de São Paulo.

ABSTRACT: The article tells, through unpublished excerpt of the diary and of correspondences, the Austrian maestro's Martin Braunwieser (1901-1991) participation in the trip of the Mission of Folkloric Researches of 1938. This ethnological expedition was the last project idealized by Mário of Andrade ahead of the Department of Culture of São Paulo.

PALAVRAS-CHAVE: Martin Braunwieser, Missão de Pesquisas Folclóricas, Mário de Andrade, Discoteca Pública Municipal, Departamento de Cultura de São Paulo.

KEYWORDS: Martin Braunwieser, Mission of Folkloric Researches, Mário de Andrade, Discoteca Pública Municipal, Department of Culture of São Paulo.

Durante o primeiro semestre de 1938, Martin Braunwieser (1901-1991), músico austríaco, residente havia dez anos no Brasil, teve oportunidade de integrar uma equipe de pesquisas etnográficas que viajou Nordeste e Norte do país. A equipe composta por quatro integrantes especializados em suas funções, foi formada por indicação de Mário de Andrade (18931945), à época mantendo o cargo de Diretor geral do
Departamento de Cultura da Municipalidade de São Paulo. A Missão de Pesquisas Folclóricas foi uma expedição pioneira, o último projeto de grande envergadura realizado na gestão de Mário de Andrade à

\footnotetext{
* Apresentado como Comunicação Oral no I Simpósio LatinoAmericano de Musicologia, Curitiba, 1997.
} 
frente da Instituição. Seu objetivo principal era efetuar pesquisas musicais gravando manifestações populares brasileiras em discos $78 \mathrm{rpm}$. Os discos e demais informes coletados estavam destinados a suprir o acervo especializado da Discoteca Pública Municipal, seção do Departamento de Cultura dirigida por Oneyda Alvarenga (1911-1984) fornecendo assim subsídios materiais para estudos e aproveitamento artístico por compositores, escritores, folcloristas e demais interessados na questão de identidade nacional em música (CARLINI, 1994, p.26-37). Durante a viagem da Missão, ocorrida de fevereiro a julho, Mário de Andrade foi definitivamente afastado do cargo de Diretor geral do Departamento de Cultura de São Paulo, "exilando-se” em seguida no Rio de Janeiro por quatro anos (CASTRO, 1989, p.19-32).

A viagem de seis meses da Missão marcou de maneira definitiva a vida de Martin Braunwieser, transformando-se em um "divisor de águas" para suas atividades após o retorno a São Paulo. Ao reassumir suas funções profissionais na capital paulista, Braunwieser orientou-se pelas influências recebidas durante a viagem da expedição. A experiência vivida naqueles seis meses consolidou definitivamente o seu processo interno de adoção do Brasil como segunda pátria.

Para os nascidos na década de 1960 em diante, será difícil lembrar-se de Martin Braunwieser. Cabe observar no entanto, que para analisar com maior profundidade a influência e significância do maestro austríaco no cenário musical brasileiro, em particular, o paulista, seria necessário algo além do que este breve artigo. Sua importância no Brasil abrange várias áreas: foi ele o criador e diretor artístico da Sociedade Bach de São Paulo (1935-1977), entidade autônoma em grande parte responsável pela valorização e entendimento de compositores como o próprio J. S. Bach e W. A. Mozart, patrocinando concertos e cursos especializados durante os seus 42 anos de existência (CARLINI, 1995, p.8). Braunwieser foi um importante pedagogo infantil, atuando de 1937 a 1964 como
Instrutor de Música nos Parques Infantis da Prefeitura de São Paulo (SANTA ROSA, 1995, p.35-51), publicando diversos trabalhos relacionados à renovação do repertório destinado à Educação Musical da criança (BRAUNWIESER, 1952; 1959). Foi professor nas disciplinas de composição, regência e teoria nos principais estabelecimentos de ensino musical da capital paulista, como o Conservatório Santa Marcelina (1948-1951), o Instituto Musical de São Paulo (19391970) e o Conservatório Estadual de Canto Orfeônico, atual Instituto de Artes da UNESP (1949-1971). Em 1945, foi membro fundador da Academia Brasileira de Música, ocupando a cadeira ${ }^{\circ} 7$, do patrono Francisco Manuel da Silva. Em 1961, foi designado para o cargo de Orientador de Canto Orfeônico da cidade de São Paulo, colaborando para a estruturação curricular da disciplina Canto Orfeônico e de seu reconhecimento oficial pelo MEC em fins de 1960 (CARLINI, 1991, p.11-12).

Pode-se perceber pelas atividades acima relacionadas, a inteira dedicação de Braunwieser em prol da música brasileira. Sua opção pelo Brasil está inteiramente articulada com a descoberta que fez do país durante a viagem da Missão de 1938. Na realidade, Braunwieser foi um homem de seu tempo, vivendo o seu presente, identificado com a proposta nacionalizante de Mário de Andrade para a música erudita do Brasil ${ }^{1}$. Um estudo aprofundado sobre o período de

\footnotetext{
${ }^{1}$ Ao contrário de outros músicos germânicos contemporâneos também atuantes no país - como Francisco Curt Lange (19031997) ou Hans J. Koellreutter (1915) - Martin Braunwieser dedicou-se intensamente à pedagogia musical, defendendo com fervor as propostas musicais apresentadas por Mário de Andrade para a sua época. Paralelamente, F. Curt Lange desenvolveu suas pesquisas em direção ao nosso passado musical, devolvendo ao conhecimento público as obras da Escola Mineira de Composição do período colonial, séc. XVIII. Hans J. Koellreutter, chegado ao Brasil em 1937, tem seu destaque histórico por haver intro-
} 
formação no Mozarteum de Salzburgo, envolvendo as primeiras atividades musicais de Braunwieser antes de sua chegada ao Brasil em 1928 - entre 1901-1927 esteve na Áustria, Croácia e Grécia - foi realizado por Antônio Alexandre Bispo, musicólogo brasileiro radicado na Alemanha, em trabalho publicado em 1991 (BISPO, 1991, p.1-100). Mesmo este volumoso trabalho faz poucas referências à participação de Braunwieser na viagem musical da Missão de Pesquisas Folclóricas. Na realidade, o estudo, a compreensão e a valorização histórica deste evento iniciou-se somente com trabalhos mais recentes (CARLINI, 1993a; 1993b; 1994).

Martin Braunwieser teve a rara oportunidade de reviver em meados do século XX a experiência de tantos viajantes estrangeiros que visitaram o Brasil durante o século XIX, como Spix, Martius, Pohl, Koseritz, Barão Langsdorff, e tantos outros provenientes do continente Europeu. Como eles, Braunwieser encantou-se com a exuberância da natureza brasileira, sensibilizou-se com as precárias condições de vida e moradia do homem do Norte e Nordeste do país, aprendendo a respeitar suas peculiaridades, o caráter e personalidade, suas manifestações espontâneas e ritualísticas, as danças e as músicas. Como os viajantes do século XIX, também Braunwieser registrou a nova experiência em um diário de viagem, que manteve distante do conhecimento público até ser redescoberto por familiares, após seu falecimento em 1991.

(...) Até quase meio-dia apenas mar por todos os lados, muito lentamente nos aproximamos da costa, a princípio uma praia muito

duzido no país as propostas e técnicas modernas de escrita musical, veiculadas a partir do pensamento Dodecafônico e Serial de Arnold Schoenberg (1874-1951), representante máximo da Segunda Escola de Viena do início do séc. XX. A influência germânica na música brasileira têm seu quadro completado com a presença desses três músicos no país: Curt Lange, atuando em favor do nosso passado musical; Martin Braunwieser, pelo presente; e Hans J. Koellreutter pelo futuro. longa e bem para trás montanhas, alguns montes e elevações bastante ressaltadas. Cada vez mais tornavam-se nítidas as formas individuais, até que pudemos distinguir claramente cada uma das montanhas de formatos tão únicos. Inesperadamente vê-se uma entrada estreita, quase como um rio desaguando no mar, e realmente lá entra o navio. Penhascos e montes em parte nus - somente a pedra é visível - alguns casebres, todas as áreas possíveis plantadas com cana-de-açúcar, árvores, ilhas maiores ou menores, para trás montanhas, e lentamente, vendo sempre mais casas, a cidade de Vitória aparece. Penso que raramente Deus deixou que aparecessem juntas tantas belezas. Qualquer pessoa com algum sentimento pela natureza ficaria encantada pelos rochedos em parte parecidos com o Pão de Açúcar no Rio, pelas suaves elevações encobertas pela floresta, e pelas pequenas casas aparecendo no entremeio; novamente, de maneira inesperada, grandes penhascos e bem para trás uma cadeia de montanhas azuladas, parte em formatos suaves depois novamente em formas inverossímeis. Por toda a volta no vale, braços de rio grandes e pequenos. Eu estava encantado. Em terra encontramos uma cidade mediana, bem espraiada, em visível desenvolvimento e como dito, situada de maneira rara junto à água e aos rochedos. Como havia pouco tempo somente pudemos empreender um rápido passeio de bonde. Ruas estreitas, bem antigas, com casas velhas - muito romântico - e ruas novas, largas ou em alargamento com algumas casas novas. O calor quase insuportável. Pela primeira vez, vi pessoas tomando água de côco nos Cafés. Esta beleza não pode ser descrita, para mim será inesquecível e se no futuro aparecer a oportunidade, virei novamente e observarei com mais atenção estas belezas naturais assim como o interior que deve ser especialmente bonito. Cada vez mais distantes ficam as montanhas, não se vê mais a costa. As altas montanhas ficam cada vez menos visíveis, o mar aberto nos recebe novamente. Até agora a mais sublime impressão desta recém-iniciada viagem $(. . .)^{2}$.

Foram seis meses de afastamento da família, dos amigos e do trabalho cotidiano. Durante esse tempo, Braunwieser pôde conhecer uma realidade inteiramente distinta de tudo o que lhe era próximo. Ele e seus companheiros de viagem enfrentaram várias si-

${ }^{2}$ Diário de viagem de Martin Braunwieser, Vitória, 9 de fevereiro de 1938. Tradução: Wolfgang Fischer, 1994. 
tuações adversas, percorrendo o interior dos Estados do Nordeste e Norte brasileiros ora a cavalo, ora na carroceria de um caminhão, terrenos desconhecidos e impróprios para qualquer espécie de tráfego. Por vezes, os integrantes da Missão tiveram poucas condições de manter a higiene pessoal. Sentiram fome e sede, dormiram mal alojados. Em seus relatos pessoais, como o diário de viagem e as correspondências à família - ainda inéditos - ou nos artigos de divulgação e estudo sobre material folclórico coletado pela equipe, Martin Braunwieser registrou suas impressões sobre o país ainda desconhecido (BRAUNWIESER, 1946a, 1946b).

À semelhança de Johann B. von Spix (1781-1826) e de Karl F. P. von Martius (1794-1849), Martin Braunwieser viajou pelo Brasil em missão oficial, delegada pelo Departamento de Cultura de São Paulo, representado na pessoa de Mário de Andrade, como Músico Responsável da Missão de Pesquisas Folclóricas, com a função múltipla de registrar, anotar, grafar melodias em notação específica, coordenar e supervisionar as gravações musicais em discos, procurando estudar o máximo possível das manifestações populares brasileiras. Como Karl Martius, Martin Braunwieser envolveu-se intensamente com a nova pátria adotiva, convertendo-se, a partir da viagem da expedição, em uma das personalidades mais diligentes para a elevação cultural e artística do Brasil, atuando de maneira decisiva no projeto de nacionalização da música erudita brasileira delineado por Mário de Andrade:

(...) Tacaratu $-6^{\mathrm{a}}$ feira -11 III - Depois de penosa viagem em um caminhão - com caminho muito ruim - chegamos ao meiodia em Brejo [dos Padres - PE], como é chamado o lugar onde moram os índios ou Caboclinhos. Ninguém aqui chama os indígenas de índios - são por toda parte conhecidos e chamados de Caboclinhos. O lugar em que vivem é um vale maravilhosamente situado. Tem-se a impressão de que aqui a terra é melhor plantada do que fora - os Caboclinhos demarcaram seu próprio território. Muitas casas pequenas a uma certa distância uma da outra, não constituindo portanto um povoado em sentido estrito. Fiquei decepcionado com os Caboclinhos. Quando espera-se encontrar certa característica racial, como esperei, só se pode ficar decepcionado. Os Caboclinhos - completamente mesclados com sangue estranho - pelo menos aqui, não se distinguem das pessoas do povoado lá fora. Muito raramente encontra-se algum traço típico em um rosto. Isso ocorre mais com os olhos: muitos têm olhos escuros que expressam quase sempre grande retraimento, tristeza e submissão. Em geral já perderam até sua própria língua: uma ou outra pessoa ainda sabe incertamente umas poucas palavras. Todos foram já absorvidos pela população local. A cor escura da pele de muitos dos Caboclinhos é notável. Cada um destes Caboclinhos tem algo em comum com os outros: o hábito da mendicância. Mal nos viramos para um lado e já aparece alguém pedindo dinheiro. A música, as danças ainda têm características, mas creio que também já influenciadas. Uma dança chama-se Praiá, dançada com as velhas roupas indígenas e com uma cantora acompanhando: isto realmente ainda é algo original. Outra dança - chamada Toré - é dançada com roupas comuns por muitas pessoas. Dois instrumentos chamados Búzios, tocam juntos e todos cantam uma melodia muito simples a duas vozes. A forma - coreográfica - é interessante. As melodias do Praiá, na minha opinião, já desapareceram: as canções vêm da boca da cantora de forma muito insegura e, parece-me, muito variável. Tive a impressão de que a cantora cantava o que queria. Para mim, de qualquer maneira, foi interessante conhecer este modo de cantar. Na volta fui a cavalo. (...) ${ }^{3}$

Além do diário de viagem, manuscrito em alemão em cerca de 150 páginas de uma pequena caderneta, Braunwieser relatou suas impressões sobre o Brasil em uma vasta série de correspondências redigidas durante o período para a esposa, a pianista de origem russa Tatiana Kipman Braunwieser (1903-1988), e para sua primogênita, Tamara Braunwieser (19331957). Também nos vários relatórios oficiais entregues à Discoteca Pública Municipal após o retorno a capital paulista, Martin narrou sua satisfação em ter participado ativamente da viagem da expedição, ci-

\footnotetext{
${ }^{3}$ Diário de viagem de Martin Braunwieser, Tacaratu, 11 de março de 1938. Tradução: Wolfgang Fischer, 1994. A palavra "caminhão" foi registrada em português no original.
} 
tando o evento como significativo para mudanças substanciais em sua vida. Esta série de correspondências - setenta e cinco cartas também manuscritas em sua língua pátria, o alemão - esteve inacessível até o momento, sendo preservada por seus familiares juntamente com o diário de viagem.

(...) Finalmente ontem, depois de uma viagem muito exaustiva, cansativa, de quinze dias sobre o caminhão, chegamos aqui em bom estado. Tu, pobrezinha, desta vez ficaste muito tempo sem notícias, mas foi melhor não postar cartas no interior. Mesmo da capital já demora tempo suficiente. Ficaremos mais cinco dias por aqui, e depois viajaremos para Belém. Mas desta vez, com um navio confiável será seguro. Em João Pessoa, todos diziam que a viagem para São Luís sempre é feita de navio, pois custa menos, é mais rápida e mais confortável. Por terra não há estradas de verdade, não há ajuda, longe ou perto, se algo se quebra. E foi exatamente o que aconteceu: péssimas estradas, erramos o caminho uma vez, e quebrou-se uma peça do carro. Por sorte, foi perto de uma cidade, pois se fosse há horas de distância desta localidade, teríamos muito a fazer. Assim, um tempo de viagem de navio de quatro, cinco dias transformou-se quinze dias por terra. Mas, enfim, chegamos.

As últimas notícias de ti, tive-as em João Pessoa: duas cartas aéreas seguidas, e no dia de nossa partida, tua carta simples de 17 de maio com as belas fotografias, pelas quais agradeço-te imensamente, pois trouxeram-me grande e profunda alegria.

Por favor, escreva-me por enquanto para: M.B., posta restante, Belém, Pará. Esta carta parte amanhã e deve alcançar-te mais ou menos quando estarei partindo daqui para Belém, onde é previsto que fiquemos mais tempo, de maneira que tuas novas alcançar-me-ão por lá. Sobre tudo o mais de nossa viagem te contarei em seguida." $(. . .)^{4}$

Para Braunwieser, a época era de grandes mudanças familiares e pessoais. Ao sair da capital paulista, em princípios de fevereiro de 1938, o maestro deixa-

\footnotetext{
${ }^{4}$ Correspondência n ${ }^{\circ}$ 54, São Luís do Maranhão, 15 de junho de 1938. Tradução de Wolfgang Fischer, 1995. A palavra "caminhão" foi grafada em português no original.
}

ra a esposa Tatiana prestes a dar a luz a sua segunda filha, Renata Braunwieser, nascida em abril daquele ano e falecida em 1987. Preocupado com o acréscimo de mais um componente na família, Braunwieser manifestar-se-á nas correspondências que manteve com Tatiana durante aquele período, o constante desejo de adquirir uma moradia própria em São Paulo, incrementar seus ganhos financeiros e conseguir guardar alguma soma para formar um pequeno patrimônio:

(...) Algumas vezes disseste-me, em tom de brincadeira, que sem minha presença em casa economizarias muito mais, que eu gasto muito dinheiro, e que na minha ausência o dinheiro ficaria em casa. Tuas palavras vieram-me à mente mais tarde, e então te escrevi, sem pensar nas consequiências, em diversas cartas seguidas, sobre a compra de uma casa, sobre pagamento de dívidas e sobre guardar dinheiro no banco. Naturalmente, com isto não pensei que tu devesses ganhar mais dinheiro. Imagino que minha postura em relação às questões financeiras talvez seja a causa inconsciente de tuas preocupações. (...) Quanto às dívidas, já te escrevi que não deves ver tudo de maneira tão trágica. Tenho certeza que Mário [de Andrade] esperará pela restituição do dinheiro se explicares a situação a ele. Devo escrever a ele? Quando eu voltar a São Paulo também ganharei mais, e logo estaremos melhor. Nos últimos dois meses tiveste despesas extras com Renata. Como escreveste, Rina morou algumas semanas conosco, e também outras pessoas vieram mais do que normalmente. Com certeza, tiveste despesas com o médico, com a farmácia, automóveis, etc. Logo, isto chega a uma soma elevada sem que se perceba direito. Acredito que hoje essas despesas extras já acabaram e em alguns meses a diferença estará acertada. Se alguma vez chegaremos a por dinheiro no banco, só Deus sabe. Nunca faltou boa vontade, mas disso nada resultou. Quando eu estiver em São Paulo, talvez possamos nos comprometer, e o que é mais importante, cumprir, a depositar mensalmente pelo menos 20-25\$ em um banco. Vais rir, isto não é nada, dirás. Desta quantia poderíamos sempre dispor mensalmente. É melhor do que nada, e se houver a possibilidade, poderíamos elevar a quantia. Pelo menos seria dado um início e com o tempo somaríamos um pequeno patrimônio. (...)" 5

${ }^{5}$ Correspondência n ${ }^{\circ} 47$ (cont. Carta n ${ }^{\circ}$ 19), João Pessoa, 27 de maio de 1938. Tradução: Wolfgang Fischer, 1995. A palavra "farmácia" foi grafada em português no original. 
Também no plano estritamente pessoal as mudanças estavam presentes. Braunwieser preocupava-se com a questão da própria nacionalidade: austríaco de nascimento, ele acompanhou a Alemanha nazista anexar sua pátria natal - um dos primeiros atos de guerra do III Reich, o Anschluss - exatamente no período de realização da viagem da Missão, época em que já havia encaminhado seu processo de naturalização brasileira, completado em 1939:

(...) Perto de João Pessoa vi um tipo de campina repleta de flores amarelas brilhantes. Isto me fez lembrar da minha pátria que agora pertence à Alemanha. Como veio rápido este Anschluss. Quanto tempo falou-se em uma guerra, e como tudo ficou aparentemente calmo. Como estarão as pessoas em Salzburgo nesta nova situação? O que fará Paumgartner? ${ }^{6}$ Será que verei de novo a minha pátria? Insisti na idéia de criar aqui no Brasil uma nova pátria para mim e sinto-me satisfeito. Que Deus dê-me forças e resistência para que eu ainda possa trabalhar muito, e após minha volta a São Paulo, que eu tenha a oportunidade de transmitir os conhecimentos adquiridos nesta viagem. $(\ldots)^{7}$

No campo profissional, as preocupações de Martin Braunwieser aumentaram após o retorno da expedição a São Paulo. Durante a viagem, em maio de 1938, Mário de Andrade foi definitivamente afastado da direção do Departamento de Cultura. Como integrante do quadro de funcionários da Prefeitura Municipal de São Paulo, atuando como instrutor de música dos Parques Infantis da capital, Braunwieser viu-se sem o apoio permanente de Mário de Andrade, seu amigo e incentivador nas atividades musicais desenvolvidas junto às crianças da capital.

Martin Braunwieser conheceu Mário de Andrade no início da década de 1930, Em 1935, com a cria-

\footnotetext{
${ }^{6}$ Bernhard Paumgartner (1887-1971) - Musicólogo austríaco, discípulo de Gustav Mahler, professor de Braunwieser no Mozarteum de Salzburg

${ }^{7}$ Diário de viagem de Martin Braunwieser, João Pessoa, 24 de março de 1938. Tradução: Wolfgang Fischer, 1994
}

ção do Departamento de Cultura de São Paulo, o relacionamento entre eles tornou-se mais estreito. Braunwieser foi convidado por Mário de Andrade para selecionar, em companhia do compositor Camargo Guarnieri (1907-1993), os cantores que iriam integrar duas novas instituições musicais criadas pelo Departamento de Cultura: o Madrigal e o Coral Paulistano. Em 1936, Braunwieser foi admitido no quadro de funcionários da Municipalidade de São Paulo, contratado para exercer a função de Maestro substituto do Coral Paulistano.

Ainda em 1936, Mário de Andrade escolheu Braunwieser para ser Maestro titular de um novo coral, destinado a agregar os interessados em canto que não possuíssem conhecimentos musicais ou treinamento vocal: o Coral Popular. A confiança de Mário de Andrade na personalidade, competência e capacidade musical de Braunwieser está claramente manifestada no ato de sua escolha. O Coral Popular foi projeto de grande significância para Mário de Andrade, criado para ser uma instituição que pudesse realizar de maneira concreta o conceito de "força socializante da música", segundo seus próprios pressupostos. De acordo com o programa impresso para o recital de estréia, realizado como parte do " $13^{\circ}$ Concerto Popular Grátis do Departamento de Cultura”, em 1936, no Teatro Municipal de São Paulo, o Coral Popular era a "primeira tentativa brasileira de reunir-se um coro popular, absolutamente sem distinção de classes nem especialização musical":

O concerto de hoje reveste-se de particular importância por ser a apresentação do Coral Popular. A bem [da verdade] esta é a primeira tentativa brasileira de reunir-se um coro popular, absolutamente sem distinção de classes nem especialização musical. Quem quer possa cantar, mesmo que não tenha conhecimentos técnicos de música, pode pertencer ao Coral Popular. Assim o nosso coro de hoje ainda não tem aquelas prerrogativas de arte com que já se pode apresentar o Coral Paulistano. É porém um esforço para o desenvolvimento entre nós do canto a várias vozes. A importância pois do Coral Popular, aquilo que deve prin- 
cipalmente tocar a compreensão dos ouvintes, é seu valor social. Universalmente se sabe que o coro é o processo musical mais perfeito para dispor o indivíduo em harmonia com os seus companheiros de organismo social. Não se trata de impor a brutal e enceguecida unanimidade, mas sim criar aquele unanimismo [sic], aquela consciência da coletividade e do organismo social que leva o homem a um equilíbrio mais perfeito entre o seu ser indivíduo e a sua forma social de ser. Quem quer tenha vivido angustiosos meses paulistas de 1932, já teve a percepção concreta do que seja esse unanimismo [sic] e esse equilíbrio sublime do ser. Mas não devemos esperar momentos trágicos da vida, as grandes calamidades públicas, as revoltas e guerras para obter o que torna o ser humano mais completo e perfeito. É preciso aproveitar as dádivas da paz para essa reeducação do indivíduo, e nada como o coro para proporcionar tal reeducação. E é com estas credenciais humanas que o Coral Popular se apresenta.

As inscrições para o Coral Popular estão permanentemente abertas no Departamento de Cultura, seção de Teatros e Cinemas, Teatro Municipal (porta dos fundos) das 12 às 17 horas". ${ }^{8}$

A escolha de Braunwieser para o Coral Popular não se deu por acaso. Amigo pessoal de Mário de Andrade, excelente pedagogo e orientador musical, Braunwieser desde o princípio identificou-se e pôde compreender a significância do projeto de nacionalização da música erudita brasileira preconizado por Mário de Andrade, transformando-se em personalidade importante empenhada no sucesso do projeto. A questão nacional no campo musical estava estreitamente vinculada à questão pedagógica. Mário de Andrade e os demais modernistas acreditavam que somente através de ampla reforma do ensino artístico seria possível incutir nos jovens uma preocupação com a cultura brasileira, preocupação esta que resultasse na modificação da mentalidade ainda Romântica dos intérpretes e professores de música.

\footnotetext{
${ }^{8}$ Programa oficial do " $13^{\circ}$ Concerto Popular Grátis do Departamento Municipal de Cultura", São Paulo, Teatro Municipal, 17 de novembro de 1936. Texto de Mário de Andrade (?).
}

Em fins de 1937, Martin Braunwieser foi convidado por Mário de Andrade para integrar a equipe de especialistas da Missão de Pesquisas Folclóricas. Mais uma vez, o maestro austríaco viu-se envolvido com o projeto de nacionalização da música erudita brasileira esboçado por Mário de Andrade. À semelhança da escolha para o Coral Popular, pode-se perceber a confiança de Mário de Andrade na seriedade e competência profissional de Braunwieser. Dez anos após a viagem etnográfica do Turista Aprendiz (19281929), Martin Braunwieser foi o escolhido para integrar a expedição, substituindo, de certa maneira, ao próprio Mário de Andrade. Coube ao maestro a responsabilidade da decisão: foi ele quem avaliou a relevância musicológica das manifestações folclóricas presenciadas pela Missão e autorizou o registro fonográfico em discos.

Iniciada em fevereiro de 1938, a Missão foi formada por quatro componentes. Além de Martin Braunwieser, faziam parte da equipe: Luiz Saia (19111975), arquiteto, membro da Sociedade de Etnografia e Folclore, pesquisador e diretor da $6^{a}$ região do Serviço do Patrimônio Histórico e Artístico Nacional (SPHAN), designado como Chefe da expedição, responsável pelos contatos políticos e oficiais e portavoz autorizado do Departamento de Cultura de São Paulo; Benedito Pacheco, colaborador da Discoteca Pública Municipal, técnico contratado do Departamento de Cultura de São Paulo e profundo conhecedor da máquina de gravação Presto Recorder utilizada na expedição, designado Técnico de Gravação; e Antônio Ladeira, indicado como auxiliar geral e assistente-técnico de gravação ${ }^{9}$.

\footnotetext{
${ }^{9}$ Todas as informações sobre a viagem da Missão foram extraídas na íntegra de: CARLINI, Álvaro - Cante lá que gravam cá: Mário de Andrade e a Missão de Pesquisas Folclóricas de 1938. Dissertação de Mestrado, FFLCH/USP. São Paulo, 1994.
} 
Em 6 de fevereiro de 1938, os componentes da Missão partiram do porto de Santos (SP) com destino ao Recife (PE), a bordo do Itapagé, embarcação da Companhia de Navegação Costeira. No dia seguinte, o Itapagé aportou no Rio de Janeiro (RJ) para uma rápida escala. Do Rio, a expedição chegou ao Recife em 13 de fevereiro, após escalas realizadas em Vitória (ES), Salvador (BA) e Maceió (CE). A Missão trabalhou em Pernambuco até 26 de março, viajando em seguida para João Pessoa, Paraíba.

Na Paraíba, as atividades da expedição foram mais demoradas: cerca de 2 meses de permanência. Durante o período de 26 de março a 30 de maio, a Missão realizou duas viagens ao interior do Estado - à zona do sertão e à zona do brejo - além de efetuar coletas próximas à capital João Pessoa. No total, os integrantes da expedição visitaram cerca de 30 localidades paraibanas. A quantidade de melodias e manifestações musicais documentadas nos discos, filmes e fotografias, supera a marca de 760, envolvendo aboios, cabocolinhos, cantos de mendigos, catimbós, cocos, nau catarineta, reis de congo, entre várias outras.

A partir de 31 de maio, com o objetivo de registrar as festas juninas tradicionais na região, a Missão deslocou-se em direção aos Estados do Norte do Brasil. Em uma viagem realizada ora em caminhão, ora por trem, a expedição partiu com destino à capital do Maranhão, percorrendo novamente o interior da Paraíba, parte do Ceará, Piauí, para atingir São Luís em 16 de junho. Durante o trajeto, ocorreram diversas paradas não planejadas devido ao esforço e desgaste imposto ao caminhão. Por 72 horas, os integrantes da expedição foram obrigados a permanecer na cidade de Jaicós, no interior do Piauí, devido à quebra do radiador do veículo.

No dia seguinte à chegada em São Luís do Maranhão, a Missão registrou a dança dramática do bumba-meu-boi e a música de feitiçaria do tamborde-mina. Em 21 de junho, a expedição partiu de São Luís com destino a Belém do Pará. Os trabalhos de gravação ocorreram entre 29 de junho a 7 de julho, com a gravação de boi-bumbás e da feitiçaria do babassuê. O regresso a São Paulo foi a bordo do navio-vapor Itanagé, também Companhia de Navegação Costeira, com escalas em São Luís (MA), Fortaleza (CE), Macau e Natal (RN), Salvador (BA), Vitória (ES), Rio de Janeiro (RJ), e, finalmente, a capital paulista onde chegaram em 21 de julho de 1938.

A participação, experiência e colaboração de Braunwieser na viagem da Missão de Pesquisas Folclóricas foi marcante sob todos os aspectos pessoais e profissionais. A expedição registrou 169 discos de acetato com várias dimensões contendo cerca de 1500 melodias de 48 manifestações musicais brasileiras. Foram registrados 12 rolos cinematográficos silenciosos de $16 \mathrm{~mm}$ documentando 12 rituais populares; 760 fotografias contendo registros de arquitetura popular e religiosa, dos informantes cantadores e de outros detalhes; cerca de 3500 páginas com anotações de letras das melodias registradas, observações sobre poética popular, um outro diário de viagem e notas diversas de autoria de Luiz Saia ${ }^{10}$, distribuídas em 15 cadernetas de campo, cadernos de música e outros papéis em escritos diferentes suportes. Constam também do material coletado pela equipe aproximadamente 600 objetos, entre instrumentos musicais, exvotos, e objetos de ritos de feitiçaria afrobrasileiros.

Após o retorno da expedição a São Paulo, todo o material coletado pela equipe foi incorporado ao acervo da Discoteca Pública Municipal (atualmente localizada no Centro Cultural São Paulo), sob os cuidados de sua diretora Oneyda Alvarenga. Enfrentando uma situação político-financeira adversa após o afastamento de Mário de Andrade do Departamento de Cultura de São Paulo, a Discoteca somente pôde iniciar o projeto de estudo e divulgação do acervo da

\footnotetext{
${ }^{10} \mathrm{O}$ diário de Luiz Saia foi transcrito e analisado integralmente em minha Dissertação de Mestrado.
} 
Missão em 1946, oito anos após o término da viagem. A história da Missão tem um final melancólico. Não obstante seu relativo sucesso como evento isolado, os objetivos fundamentais dessa expedição - a divulgação, estudo e aproveitamento do acervo folclórico registrado, para fornecer subsídios materiais ao projeto de nacionalização da música brasileira - foram somente consumados, ainda de maneira insatisfatória, com o passar dos anos ${ }^{11}$. A intenção inicial de realizar a transcrição em notação musical dos fonogramas gravados pela Missão foi iniciada em 1946 sob responsabilidade do compositor Camargo Guarnieri, contrariando a óbvia expectativa de contratação de Martin Braunwieser. Guarnieri, no entanto, realizou apenas transcrições musicais experimentais de pequena parte do acervo, que permanecem, a exemplo de

\section{Bibliografia}

BISPO, Antônio. Martin Braunwieser - Espiritualismo, nova objetividade, humanismo clássico e as tradições do oriente e do ocidente na pedagogia e na criação artística: contribuição ao estudo da influência austríaca e alemã na música do Brasil no século XX. Alemanha, Köln, Consociatio Internationalis Musicae Sacrae; Institut fur Hymnologische und Musikethnologische Studien, 1991. 329p. [Musices aptatio: Liber Annuarius]

BRAUNWIESER, Martin. "Cegos pedintes cantadores do nordeste". Boletin Latino-Americano de Musica, Montevidéu, vol. 6, 1946, p.323-329.

${ }^{11}$ Oneyda Alvarenga organizou ao longo dos anos de 1940-60, 2 coleções destinadas à divulgação do acervo: Arquivo Folclórico da Discoteca Pública Municipal, com 2 volumes publicados; e praticamente toda a coleção documentada pela equipe, ainda hoje, inéditas.

É importante ressaltar que Martin Braunwieser não divulgou suas anotações de viagem da Missão de Pesquisas Folclóricas em vida. Nem mesmo os seus familiares mais próximos sabiam da existência do seu diário pessoal e da sobrevivência, por mais de 50 anos, das cartas escritas à esposa Tatiana durante a expedição. Após o falecimento do maestro em 1991, em organização efetuada em sua residência por parentes, esses documentos pessoais foram localizados, acondicionados e protegidos por envelope plástico. A possibilidade de estudo desse importante acervo pessoal foi facultada pela família que compreendeu o valor da documentação, e permitiu a tradução do alemão para o português e a conseqüente divulgação.

BRAUNWIESER, Martin. "O cabaçal". Boletin Latino-Americano de Musica, Montevidéu, vol. 6, 1946, p.601-606.

BRAUNWIESER, Martin. 25 brinquedos cantados: populares infantis. São Paulo, Irmãos Vitale Ed., 1952, 55p.

BRAUNWIESER, Martin. 25 rodas cantadas: populares infantis. São Paulo, Irmãos Vitale Ed., 1959, 58p.

CARLINI, Álvaro \& LEITE, Egle Alonso. Catálogo históricofonográfico Discoteca Oneyda Alvarenga. São Paulo, Centro Cultural São Paulo, 1993, 143p, [Série Catálogo Acervo Histórico n.1]

CARLINI, Álvaro. "A Sociedade Bach de São Paulo (19351977)". Informativo Carlos Gomes, 1(3): 1-8, 1995.

Registros Sonoros de Folclore Musical Brasileiro, com 5 volumes, destinados a subsidiar a audição dos discos registrados pela Missão de Pesquisas Folclóricas. 
CARLINI, Álvaro. Cachimbo e maracá: o catimbó da Missão (1938). São Paulo, Centro Cultural São Paulo, 1993. 221p.il.

CARLINI, Álvaro. Cante lá que gravam cá: Mário de Andrade e a Missão de Pesquisas Folclóricas de 1938. São Paulo, 1994. [Dissertação de Mestrado - FFLCH/USP]

CARLINI, Álvaro. "Maestro Martin Braunwieser". D.O.Leitura,
10 (110):11-12, 1991.

CASTRO, Moacir Werneck. Mário de Andrade: exílio no Rio. Rio de Janeiro, Rocco, 1989, 237p.

SANTA ROSA, Nereide Schilaro. "A educação musical na escola municipal de educação infantil da cidade de São Paulo". Revista ARTEunesp, São Paulo, 11: 35-51, 1995 